\title{
The effect of US omission in classical aversive and appetitive conditioning of rabbits
}

\author{
WILLIAM F. PROKASY \\ University of Utah, Salt Lake City, Utah 84112 \\ and \\ I. GORMEZANO \\ University of lowa, Iowa City, Iowa 52240
}

\begin{abstract}
Rabbits (Oryctolagus cuniculus) were given either a $100 \%$ or a $50 \%$ reinforcement schedule in classical conditioning. Two groups received an aversive US (shock) and two groups received an appetitive US (water to the oral cavity). With parameter estimates for the twophase model serving as the dependent variables, it was possible to define more precisely the effect of US omission with the intermittent reinforcement schedule. For the aversive preparation, the major effect of intermittent reinforcement was to increase the duration of Phase 1, a phase during which response likelihood remains constant at its initial value. Only a small proportion of subjects reflected the effect of US omission during Phase 2, the "learning" phase, this being a low operator limit following trials on which neither the CR nor the US occurred. The major effect of US omission for the appetitive preparation was in Phase 2, primarily a result of a minority of subjects having a low operator limit following trials on which neither the CR nor the US occurred. Many subjects required separate operators for trials on which the CR did or did not occur. The results were interpreted to pose difficulties for strength theories of conditioning, and the limitation implied for successful application of the Rescorla-Wagner theory are discussed. The implications of the data for response-contingent interpretations and for individual differences are also discussed.
\end{abstract}

Strength theories of conditioning (e.g., Bush \& Mosteller, 1955; Estes, 1950; Perkins, 1968; Rescorla \& Wagner, 1972; Spence, 1956, 1960) share a common characteristic: whether there is an increment or decrement in response strength following a specified trial depends upon that trial's outcome. Thus, with a $100 \%$ reinforcement schedule, the two possible trial outcomes are CR-US and $\overline{C R}$-US (where CR and US are, respectively, conditioned response and unconditioned stimulus). With an intermittent reinforcement schedule, two additional trial outcomes are possible: CR- $\overline{\mathrm{US}}$ and $\overline{\mathrm{CR}}-\overline{\mathrm{US}}$. With the exception of that of Bush and Mosteller, the cited theories all specify that the first two trial outcomes yield an increment in response strength and that the latter two yield a decrement in response strength. As a model deriving from no theory, the Bush-Mosteller linear operator system is neutral with respect to expected trial outcomes.

Not all theoretical accounts of conditioning imply that presence vs. absence of the US is the unique

This research was supported by NSF Grants BNS 75-10471 and BNS 76-84561, awarded, respectively, to William F. Prokasy and I. Gormezano. We would like to thank Craig Clark for his aid in data processing. determiner of increments or decrements in response strength. For example, a strict law-of-effect interpretation (e.g., Hebb, 1956) implies increments only following a CR-US trial outcome because the critical element in acquisition is assumed to be the interaction of CR and US, and the result is that a decrement (or no change) would be expected following each of the other three kinds of trial outcome. Alternatively, the contiguity theory underlying the stimulus sampling model (e.g., Estes, 1950) requires increments following both CR-US and $\overline{C R}$-US trials but, depending upon the particular assumptions, might also require increments following CR- $\overline{U S}$ trials in view of the fact that a response does occur.

All of the cited theories do imply, however, that a $100 \%$ reinforcement schedule should result in a greater performance level than an intermittent (e.g., $50 \%$ ) reinforcement schedule. As Gormezano and Moore (1969, p. 166) illustrate, it has not uniformly been the case that intermittent reinforcement schedules have resulted in reduced (relative to $100 \%$ reinforcement) performance levels, an outcome clearly indicating limitations to the application of such strength theories. Of particular interest in the present paper is classical conditioning with rabbit subjects. The two available studies (Gormezano \& Coleman, 
1973; Thomas \& Wagner, 1964) on aversive conditioning of, respectively, the nictitating membrane and the eyelid responses show comparable results: intermittent reinforcement retards initial acquisition, but asymptotic performance is only slightly below that obtained with $100 \%$ reinforcement. Gormezano and Coleman (1973) have also shown that response probability did not increase following a succession of reinforced trials differentially with respect to a succession of nonreinforced trials. This withinsequence result is contrary to expectations based upon strength theories, and contrasts with the increments (following reinforced trials) and decrements (following nonreinforced trials) obtained in human aversive conditioning (Prokasy, Carleton, \& Higgins, 1967).

The purpose of this paper is to analyze the effects of the various trial outcomes with intermittent reinforcement and to contrast these effects with those obtained with a $100 \%$ reinforcement schedule. The analysis will be made with the two-phase model, a model which has been successful in describing performance in aversive conditioning (e.g., Prokasy, 1972, 1973; Prokasy \& Harsanyi, 1968). The model is two phase in that, during Phase 1 , no performance changes occur and, during Phase 2, increments and decrements can occur, depending upon trial outcome. Phase 2 is described with a set of linear operators, one for each possible trial outcome, and is, therefore, the same as that proposed initially by Bush and Mosteller (1955, p. 286). $\mathrm{P}_{\mathrm{i}}$, response probability on Trial $\mathrm{i}$, is expressed as:

$$
\begin{aligned}
& P_{i}=P_{0}, i \leqslant K \\
& P_{i}=P_{i-1}+\theta_{1}\left(\lambda_{1}-P_{i-1}\right), \quad i>K, \quad C R, \quad U S \\
& \text { on Trial } i-1 \\
& P_{i}=P_{i-1}+\theta_{2}\left(\lambda_{2}-P_{i-1}\right), \quad i>K, \quad \overline{C R}, \quad U S \\
& \text { on Trial } i-1 \\
& P_{i}=P_{i-1}+\theta_{3}\left(\lambda_{3}-P_{i-1}\right), \quad i>K, \quad C R, \overline{U S} \\
& \text { on Trial } i-1 \\
& P_{i}=P_{i-1}+\theta_{4}\left(\lambda_{4}-P_{i-1}\right), i>K, \overline{C R}, \overline{U S} \\
& \text { on Trial } i-1
\end{aligned}
$$

where $P_{0}$ is the base level of response probability prior to conditioning, $K$ is the trial on which $S$ switches from Phase 1 to Phase 2, the $\theta$ s are growth parameters, and the $\lambda s$ are limits. Since parameters are estimated separately for each subject in each treatment, it is possible to use the obtained estimates as dependent variables to identify the locus of any effects of the intermittent reinforcement schedule.

Though the model is a descriptive one, it is to be noted that the transformation of response probability specified in the above equations must occur after a trial is over, i.e., after the outcome (CR presenceabsence, US presence-absence) of a trial is available to the organism. This necessarily implies some form of posttrial processing, an implication fully consistent with the outcome of recent research on short-term memory processing by Wagner and his associates (e.g., Wagner, 1976; Wagner, Rudy, \& Whitlow, 1973).

The first problem is to determine whether intermittent reinforcement, as contrasted to $100 \%$ reinforcement, has its effect in Phase 1, Phase 2, or both. It has been suggested (Prokasy, Clark, Williams, $\&$ Spurr, 1974) that Phase 1 may be interpreted as a phase during which the subject identifies contingencies and selects a response category, and it is entirely possible, based upon past data with rabbit subjects (Gormezano \& Coleman, 1973; Thomas \& Wagner, 1964), that the intermittent pairing of CS and US extends the duration of Phase 1 with little or no effect subsequent to Trial K. Since the available rabbit aversive-conditioning data suggest comparable performance limits for intermittent and $100 \%$ reinforcement schedules, any effect of the former schedule during Phase 2 would appear to be confined to a reduction in $\theta$. A question of particular importance, however, is the way in which the parameter estimates for the two operators in common to intermittent and $100 \%$ reinforcement (i.e., those applying to CR-US and $\overline{C R}$-US trials) differ. Are these estimates the same, and is, therefore, any Phase 2 effect of intermittent reinforcement confined to the two trial outcomes which are unique to that schedule? Finally, in what ways do the trial outcomes conform to the expectations derived from various strength theories?

Two sets of data were employed in this study. The first set compared $50 \%$ and $100 \%$ reinforcement schedules in aversive nictitating membrane conditioning in the rabbit, and the second compared $50 \%$ and $100 \%$ schedules in appetitive jaw-movement conditioning in the rabbit.

\section{METHOD}

\section{Experiment 1a}

Subjects. The subjects were 41 male and female albino rabbits, 80-100 days old, and each weighed approximately $2 \mathrm{~kg}$ on arrival at the laboratory.

Apparatus. The conditioning chambers, apparatus, and technique for recording the nictitating membrane responses have been described by Coleman and Gormezano (1971), who detail departures from earlier specifications (Gormezano, 1966; Gormezano, Schneiderman, Deaux, \& Fuentes, 1962). The CS was an 80-dB, $300-\mathrm{msec}, 1,000-\mathrm{Hz}$ tone, and the US was a $50-\mathrm{msec}, 4-\mathrm{mA}, 60-\mathrm{Hz}$ shock delivered to the subject's paraorbital region through two stainless steel Autoclip sutures positioned $10 \mathrm{~mm}$ apart and $15 \mathrm{~mm}$ dorsal to the right external eyelid. The CS-US interval was $250 \mathrm{msec}$.

Procedure. All subjects received 1 day of preparation followed by a 2 -day recovery period, 1 day of adaptation, and 2 days of 
acquisition training consisting of 200 trials per day. On the preparation day, a small loop of monofilament nylon was sutured into the right nictitating membrane, the surrounding hair was removed, and the US electrodes were implanted. On the adaptation day, the restrained rabbits were placed in the conditioning chambers with recording apparatus attached for a period of $1 \mathrm{~h}$. For acquisition, 19 and 22 subjects were randomly assigned, respectively, to each of two groups: a random $50 \%$ reinforcement group and continuous $100 \%$ reinforcement group. Reinforced and nonreinforced trials for the $50 \%$ reinforcement group were determined within 20-trial blocks, with a run-length restriction of 3 . All subjects received their trials at random intertrial intervals of 50,60 , and $70 \mathrm{sec}$ and a mean of $60 \mathrm{sec}$. A CR was defined as a membrane extension of $.5 \mathrm{~mm}$ or more, occurring within $250 \mathrm{msec}$ after onset.

\section{Experiment 1b}

Subjects. The subjects were 66 male and female albino rabbits, 80-100 days old, and each weighed approximately $2 \mathrm{~kg}$ on arrival at the laboratory.

Apparatus. The conditioning chambers, apparatus, and technique for recording the jaw-movement response have been described by Mitchell and Gormezano (1970), who detail departures from earlier procedures (Smith, DiLollo, \& Gormezano, 1966). The US was a 1-nil squirt of water delivered into the subject's oral cavity over a period of $300 \mathrm{msec}$ via a polyethylene cannula in the subject's left cheek. The US was delivered at the termination of a $500-\mathrm{msec}, 100-\mathrm{Hz}, 80-\mathrm{dB}$ tone $\mathrm{CS}$, yielding a 500 -msec CS-US interval.

Procedure. The subjects were anesthetized on the 3rd day after their arrival, a polyethylene cannula was permanently inserted through a fistula in the left cheek and a wound clip applied to the lower jaw to permit jaw-movement recording. After a 48-h recovery period, the subjects were restricted to $60 \mathrm{ml}$ of water per day for 5 successive days. Prior to the availability of water on the 5th day, the subjects were adapted to the apparatus and their jaw movements recorded at times corresponding to the observation interval of subsequent acquisition sessions. Acquisition training was begun on the following day, with 34 and 32 subjects randomly assigned to a random $50 \%$ and continuous $100 \%$ reinforcement group, respectively. All subjects received 8 days of acquisition training consisting of 30 trials per day at random intertrial intervals of 160,180 , and $200 \mathrm{sec}$ and a mean of $180 \mathrm{sec}$. A CR was defined as a jaw movement of $.5 \mathrm{~mm}$ or more, occurring within $500 \mathrm{msec}$ after CS onset. For the random $50 \%$ reinforcement group, reinforced and nonreinforced trials were within 30-trial blocks, with a run-length restriction of 3 . To maintain all subjects under the same $60-\mathrm{ml}$ water-maintenance regimen, the rabbits in the random $50 \%$ reinforcement group had $45 \mathrm{ml}$ and the continuous reinforcement group had $30 \mathrm{ml}$ of water available in their home cages at the end of each acquisition session.

\section{RESULTS}

Mean performance level in blocks of 20 trials is provided in Table 1 for all four groups. There were 20 blocks of trials in Experiment $1 \mathrm{a}$ and 12 in Experiment $\mathbf{1 b}$. Analyses of variance were conducted in two ways: Over all trial blocks and then over the final six blocks to assess differences in terminal performance. The results of these analyses are reported in Table $2 .^{1}$ With the aversive preparation, both the Groups main effect and the Groups by Trials interaction were significant when conducted over all trial blocks. In spite of the systematic superiority of Group $100 \mathrm{AV}$ across the final trial blocks, the difference was not reliable at asymptote. With the appetitive preparation, there were also reliable between-groups effects, with the analyses revealing that the $100 \%$ schedule yielded the greater performance both across all blocks and across the final six blocks.

\section{Parameter Estimation}

Parameters were estimated separately for each subject with the use of the computer subroutine STEPIT. Since recent simulation work (Clark \& Prokasy, 1976) has shown that detecting withinsubject differences in $\theta$ is not likely with $\theta$ values generally above .1, the simplifying assumption that $\theta_{1}=\theta_{2}=\theta_{3}=\theta_{4}$ was made. This permitted an emphasis on differences in $\lambda$ on a within-subjects basis, the most critical parameter for theoretical purposes, while allowing for between-groups differences in overall $\theta$. The subjects were classified into one of four assumption categories, given a $\theta$ common to all four possible operators:

$$
\begin{array}{ll}
\text { A } & \lambda_{1}=\lambda_{2}=\lambda_{3}=\lambda_{4} \\
\text { B } & \lambda_{1}=\lambda_{2} \neq \lambda_{3}=\lambda_{4} \\
\text { C } & \lambda_{1}=\lambda_{3} \neq \lambda_{2}=\lambda_{4} \\
\text { D } & \lambda_{1} \neq \lambda_{2} \neq \lambda_{3} \neq \lambda_{4}
\end{array}
$$

Table 1

Mean Response Probability Over Blocks of 20 Trials in Both Aversive and Appetitive Preparations

\begin{tabular}{lllllllllll}
\hline AV 100 & .247 & .482 & .653 & .716 & .716 & .721 & .811 & .839 & .847 & .853 \\
& .882 & .858 & .816 & .868 & .866 & .921 & .950 & .958 & .963 & .955 \\
AV 50 & .063 & .063 & .105 & .208 & .332 & .442 & .476 & .516 & .576 & .645 \\
& .584 & .713 & .703 & .745 & .853 & .882 & .868 & .882 & .879 & .889 \\
AP 100 & .067 & .231 & .359 & .616 & .590 & .595 & .769 & .712 & .724 & .753 \\
& .760 & .678 & & & & & & & \\
AP 50 50 & .050 & .105 & .205 & .264 & .338 & .388 & .459 & .493 & .517 \\
\hline
\end{tabular}


Table 2

Summary of ANOVA of Response Probability for Aversive and Appetitive Preparations

\begin{tabular}{lrrrrr} 
& \multicolumn{2}{c}{ All Trials } & \multicolumn{2}{c}{ Last Six Blocks } \\
& df & F & df & F \\
\hline & \multicolumn{2}{c}{ Aversive } & & \\
Groups & 1 & $14.57^{*}$ & 1 & 1.03 \\
Subjects/Groups & 36 & $(.6594)$ & 36 & $(.2005)$ \\
Blocks & 19 & $40.64^{*}$ & 5 & 1.79 \\
G by B & 19 & $5.02^{*}$ & 5 & .61 \\
Subjects by B/Groups & 684 & $(.0475)$ & 180 & $(.0124)$ \\
& \multicolumn{2}{c}{ Appetitive } & & \\
Groups & 1 & $9.69^{*}$ & 1 & $8.20^{*}$ \\
Subjects/Groups & 62 & $(.4145)$ & 62 & $(.3105)$ \\
Blocks & 11 & $108.44^{*}$ & 5 & $5.95^{*}$ \\
G by B & 11 & $2.06^{*}$ & 5 & $2.21^{*}$ \\
Subjects by B/Groups & 682 & $(.0341)$ & 310 & $(.0257)$ \\
\hline
\end{tabular}

Note-Three subjects in Group $A V 50$ and two from Group AP 50, all selected at random, were dropped from the analyses to produce groups of equal size within each analysis. ${ }^{*} p<.05$

Subscripts 1 and 2 refer to reinforced trials with, respectively, $\mathrm{CR}$ and $\overline{\mathrm{CR}}$ outcomes, while subscripts 3 and 4 refer to nonreinforced trials with, respectively, $C R$ and $\overline{C R}$ outcomes. Assumption $A$ states that once subjects enter Phase 2 , the posttrial transformation of response probability is independent of both $C R$ presence-absence and US presence-absence on the immediately preceding trial. Assumption B states that the limit approached in the posttrial transformation of response probability is a function of US presence vs. absence on the immediately preceding trial. Assumption $\mathrm{C}$ states that the limit approached is a function of $C R$ presence vs. absence on the immediately preceding trial, and Assumption D states that the limit approached is a joint function of both CR presence-absence and US presence-absence on the immediately preceding trial. ${ }^{2}$

The subjects were categorized in one of the four above assumption categories based on procedures described in detail elsewhere (Clark \& Prokasy, 1976; Prokasy, 1973). Suffice it to say here that the likelihood of classifying a subject incorrectly from, say, Assumption A to either Assumption B or Assumption $C$ is approximately .11. On the other hand, if either Assumption B or Assumption C were the "correct" category, the likelihood of misclassifying a subject into Assumption A would be, by current simulation estimates, approximately .24. Thus, classification errors tend somewhat to bias toward Assumption A.

\section{Assumption Categories}

Table 3 provides the means of the parameter estimates for each group. The means are presented separately for each assumption category, together with the number of subjects falling into each category.
The most striking feature of Table 3 categories is that not a single subject in either the appetitive or the aversive preparation was categorized under Assumption B. Under that assumption, the limits associated with reinforced and nonreinforced trials would differ. However, based strictly upon categorization of subjects, there is some evidence of an intermittent reinforcement effect during Phase 2. First, a total of six subjects, three each in the two preparations, required Assumption D, an assumption which states that there are at least three different limits. Nonetheless, even in those six subjects, two facts are evident: There is still a powerful CR presenceabsence difference in operator limits, and the major impact of the absence of the US was to produce very low operator limits for those trials which included neither a CR nor a US; second, there was a shift, in the aversive preparation, in the proportion of subjects categorized under Assumptions $A$ and $C$. The proportion of Assumption $C$ subjects was greater with $50 \%$ reinforcement than with $100 \%$ reinforcement $\left[\chi^{2}(1)=6.26\right]$. The same directional effect was present with the appetitive preparation but it was not significant.

\section{Parameter Estimates}

Since there were no reliable differences in $\mathbf{P}_{0}$, either as a function of reinforcement ratio or as a function of categories within a treatment, there will be no further discussion of this empirically estimated parameter. For both the aversive and the appetitive preparations, mean $\mathrm{K}$ (combined across assumption categories) was greater with the $50 \%$ than with the $100 \%$ schedule, though the effect was significant only with the aversive preparation [t(39) $=4.35]$.

There was only one statistically significant outcome with $\theta$ as the dependent variable. In the appetitive preparation with $100 \%$ reinforcement, the

Table 3

Mean Parameter Estimates for Each Assumption Category (AC) Across Aversive and Appetitive Treatments

\begin{tabular}{|c|c|c|c|c|c|c|c|c|}
\hline $\begin{array}{l}\text { Treat- } \\
\text { ment }\end{array}$ & $\mathrm{AC}$ & $\mathbf{N}$ & $\mathrm{K}^{*}$ & $\theta^{*}$ & $\lambda_{1}$ & $\lambda_{2}$ & $\lambda_{3}$ & $\lambda_{4}$ \\
\hline AV 100 & $\begin{array}{l}\text { A } \\
\text { C }\end{array}$ & $\begin{array}{r}9 \\
10\end{array}$ & $\begin{array}{l}7.5 \\
7.5\end{array}$ & $\begin{array}{l}.209 \\
.209\end{array}$ & $\begin{array}{l}.965 \\
.965\end{array}$ & $\begin{array}{l}.965 \\
.162\end{array}$ & $\begin{array}{l}.965 \\
.965\end{array}$ & $\begin{array}{l}.965 \\
.162\end{array}$ \\
\hline AV 50 & $\begin{array}{l}\text { A } \\
\text { C } \\
\text { D }\end{array}$ & $\begin{array}{r}2 \\
17 \\
3\end{array}$ & $\begin{array}{l}53.9 \\
53.9 \\
53.9\end{array}$ & $\begin{array}{l}.175 \\
.175 \\
.175\end{array}$ & $\begin{array}{l}.975 \\
.953 \\
.960\end{array}$ & $\begin{array}{l}.975 \\
.123 \\
.420\end{array}$ & $\begin{array}{l}.975 \\
.953 \\
.930\end{array}$ & $\begin{array}{l}.975 \\
.123 \\
.063\end{array}$ \\
\hline AP 100 & $\begin{array}{l}\text { A } \\
\text { C }\end{array}$ & $\begin{array}{l}16 \\
16\end{array}$ & $\begin{array}{l}34.6 \\
34.6\end{array}$ & $\begin{array}{l}.317 \\
.317\end{array}$ & $\begin{array}{l}.787 \\
.839\end{array}$ & $\begin{array}{l}.787 \\
.283\end{array}$ & $\begin{array}{l}.787 \\
.839\end{array}$ & $\begin{array}{l}.787 \\
.283\end{array}$ \\
\hline $\mathrm{AP} \quad 50$ & $\begin{array}{l}\text { A } \\
\text { C } \\
\text { D }\end{array}$ & $\begin{array}{r}13 \\
18 \\
3\end{array}$ & $\begin{array}{l}41.1 \\
41.1 \\
41.1\end{array}$ & $\begin{array}{l}.317 \\
.317 \\
.317\end{array}$ & $\begin{array}{l}.775 \\
.827 \\
.840\end{array}$ & $\begin{array}{l}.775 \\
.118 \\
.480\end{array}$ & $\begin{array}{l}.775 \\
.827 \\
.610\end{array}$ & $\begin{array}{l}.775 \\
.118 \\
.000\end{array}$ \\
\hline
\end{tabular}

*These values were pooled across all subjects within each treatment, and hence are listed as the same for each assumption category within that treatment. 
value of $\theta$ was reliably greater for Assumption $\mathrm{C}$ than for Assumption A subjects [t $(30)=2.13]$.

The pattern of $\lambda$ estimates exhibits a surprising uniformity across reinforcement schedules. For example, $\lambda_{1}$ does not vary reliably as a function of assumption category within either the appetitive or the aversive preparations. The one statistically reliable result associated with the limits is that in the appetitive preparation $\lambda_{2}$ was less for Assumption C subjects with $50 \%$ reinforcement than with $100 \%$ reinforcement.

\section{DISCUSSION}

\section{Reinforcement Schedule}

Consistent with past research (Gormezano \& Coleman, 1973; Thomas \& Wagner, 1964), the present data show clearly that an intermittent reinforcement schedule retards the acquisition of conditioned responses in rabbit subjects. What the present analysis illustrates is where the schedule has its effect and how the effect differs across the two motivational systems employed.

In the aversive preparation, the major effect of the $50 \%$ schedule was a marked increase in the duration of Phase 1. Phase 2 effects were confined to a small number of subjects which exhibited a difference between $\lambda_{2}$ and $\lambda_{4}$-response probability decreased toward a lower limit following a $\overline{\mathrm{CR}}-\overline{\mathrm{US}}$ trial than following a $\overline{\mathrm{CR}}$-US trial. Although the intermittent reinforcement schedule did not affect the values of the parameter estimates during Phase 2 , it did increase the proportion of subjects requiring only a single operator to describe Phase 2. This will be discussed further below.

The small, nonsignificant, difference in asymptotic performance between the two aversive reinforcement schedules is describable with the increase in proportion of subjects requiring two operators as well as with the minority whose performance did, to some extent, reflect the aftereffects of US omission during Phase 2. Presumably, the differences would be significant by conventional contrasts between overall performance limits with an increase in the size of the sample and, therefore, a greater number of subjects exhibiting reductions in response probability under Assumptions C and D.

\section{Incremental-Decremental Theories}

The results of the present analysis raise considerable difficulties for strength theories of conditioning. Consistent with past outcomes (e.g., Gormezano \& Coleman, 1973; Prokasy et al., 1974) a strict law-ofeffect interpretation of conditioning (see, e.g., Hebb, 1956) has difficulties, if for no other reason than that high $\lambda$ s are associated with trials other than CR-US trials. The Rescorla-Wagner (Rescorla \&
Wagner, 1972) and Spence $(1956,960)$ theories have been successful in accounting for the increases in performance associated with CR-contingent increases in US intensity (Clark \& Prokasy, 1976; Gormezano \& Coleman, 1973) and for the acquisition of a discriminated punishment CR in humans (Prokasy et al., 1975), but do encounter serious difficulty with the present data. The theoretical requirement is that decrements follow $\overline{\mathrm{US}}$ trials, yet this occurred in very few subjects in either preparation. Similarly, a contiguity interpretation (e.g., Estes, 1950) requires at the very least that a decrement in response probability follow $\overline{\mathrm{CR}} \cdot \overline{\mathrm{US}}$ trials. This requirement was met by only a total of 6 of the 107 subjects. While a significant number of additional subjects did have a low limit associated with $\overline{\mathrm{CR}}-\overline{\mathrm{US}}$ trials, this result was coupled with the same low limit on $\overline{\mathrm{CR}}-\mathrm{US}$ trials. This latter kind of trial outcome is theoretically intolerable for contiguity theory, because it is the US elicitation of a response which forms the initial basis of $C R$ acquisition.

Since it has been a remarkably successful theory, the Rescorla-Wagner model (Rescorla \& Wagner, 1972; Wagner \& Rescorla, 1972) merits further examination with respect to the implications of the failure for US omission to result in significant decrements in response probability. According to that theory, associative strength increases with each CS-US pairing, toward a limit determined by what the US can support. Associative strength decreases with each US omission toward a limit provisionally set at zero. By adding the assumption that the discrepancy between the limit and the signal value of the total aggregate of available cues determines the size of change in associative strength (or expectancy) with each trial (see, e.g., Wagner, 1976), these theorists have been able to account for an array of phenomena, such as blocking, overshadowing, conditioned inhibition, and, in general, excitatory-inhibitory interactions (however, see Spurr, Note 1).

There are at least two levels of analysis for which the theoretical model has implications. The first is the most commonly employed and is the one on which the above successes are based. A qualitative ordering of outcomes contrasting two or more groups (or two or more stimuli within groups) is predicted based upon the theoretical constructs and the equations employed to make derivations. Thus, US omission to a compound, AX, intermixed with Pavlovian pairings of element $A$ with the US does produce conditioned inhibition. In addition, when $\mathrm{X}$ is compounded with cues having greater associative strength, greater conditioned inhibition is exhibited (Rescorla \& Wagner, 1972, p. 70-73). Support for such ordered predictions not only indicates the predictive power of the theory, but also provides, within the context of that theory, clear evidence of conditioned inhibition. 
The second level of analysis is not commonly employed but is just as germane to the theory. This is an analysis of the microstructure of the data. In this case, we refer to the response sequence of individual subjects over trials. To make derivations of the kind described above implies strong assumptions about what happens as a consequence of successive reinforced and nonreinforced trials. Specifically, conditioned inhibition can be predicted only with the assumption that associative strength decreases with US omission and increases with US occurrence. Similarly, the account of intermittent reinforcement discussed by Rescorla and Wagner (1972, p. 81-86) in connection with discrimination learning requires increments and decrements in associative strength corresponding to US presence vs. absence. It is precisely at this microstructure level that the theory experiences difficulties; the decrements which should occur with US omission are marginal at best. ${ }^{3}$ Accordingly, what we have is a situation in which the theory is successful in making ordered predictions, but in which there is too little evidence for the theoretical process assumed in deriving some of the predictions. The value of the theory is compromised under these circumstances, since adequate accounts of the data are required at both the ordered prediction and microstructure levels of analysis.

As one alternative, it is possible that associative strength is acquired rapidly in relatively few trials, i.e., during Phase 1 , and is virtually stabilized by the time the subject enters Phase 2 . Such a view has some credibility when it is recognized that there is evidence that CS-US contingencies are learned rapidly (Prokasy, 1965, 1972; Schneiderman, 1972) and that multipleunit dorsal hippocampal activity is observed within 10 CS-US presentations (e.g., Berger \& Thompson, 1978; Thompson, 1976). If the structure of associations that is acquired transcends individual trials and permits "knowledge" of the kind of schedule being presented, the response levels achieved during Phase 2 might well reflect response levels supportable by the US independent of the particular reinforcement ratio. That is, continuation of a learned reinforcement schedule may not produce departure from an associative structure because the nature of the reinforcement schedule is part of that learned structure.

The introduction of US omission with discriminable stimuli in a fashion which permits, for example, the creation of a conditioned inhibitor during Phase 2 may well produce a different associative structure (e.g., detection of the fact that a particular signal is specifically correlated with US omission), one which is not a consequence so much of a sequence of US presentations and omissions as of a contrast between the conditions under which the US does and does not occur. If this is true, then it is apparent that the Rescorla-Wagner model cannot be applied as they have suggested. There are two reasons for this. The first is that it would not then be clear to what the equations applied. The associative network would largely be acquired prior to response learning, and the model would then have no referent in the data; theoretical derivations could not then logically be related to data. Second, if it is maintained that the model does apply in Phase 2, perhaps reflecting changes in US representation following associative learning (see, e.g., Rescorla \& Heth, 1975), then it is apparent that the decremental effect of US omission takes place only under special experimental circumstances, and these remain to be specified. Simple US omission would not then be a sufficient condition for decremental effects, as is now implied by the RescorlaWagner model.

One obvious possibility, consistent with the proposition that supratrial information is acquired by the subject, is that the limit of associative strength with US omission is not always zero but can become whatever the US strength will support in situations in which there is no discriminable information about whether or not the US will occur following CS presentation. Such a view does not do violence to the account of various inhibitory phenomena provided by the Rescorla-Wagner theory, but it does render inadequate the interpretation of the effects of nonreinforcement during pseudodiscrimination (i.e., intermittent reinforcement) learning.

\section{Appetitive vs. Aversive Preparations}

There are necessarily limitations in contrasting the results of the two preparations because aversiveness and appetitiveness have not been scaled. For example, it is known (Prokasy \& Harsanyi, 1968) that increasing US intensity reduces $K$, hence decreasing the duration of Phase 1 . It is entirely possible that the large difference in $\mathrm{K}$ which appeared in the aversive preparation as a function of reinforcement schedule as contrasted with the small difference in the appetitive preparation results from an interaction of US intensity with schedule; if the water US was not highly appetitive, it may have been sufficient to delay onset of performance increments in a way which overshadows what otherwise might have been a reinforcement ratio effect. However, in spite of the limitation to comparisons between appetitive and aversive preparations, it is notable that the general pattern of Phase 2 outcomes was the same for both: very little impact of the intermittent reinforcement schedule; high limits associated with CR trials; and no difference in the general pattern of Assumptions $A$ and $C$ subjects as a function of reinforcement schedule. Though an entirely appropriate comparison would involve an analysis of patterns of parameter estimates as a function of, for example, US intensity, the present data strongly suggest that the incremental- 
decremental effects observed do not vary in any significant way as a function of quality of the US.

\section{CR Presence-Absence}

As in past studies (e.g., Clark \& Prokasy, 1976; Prokasy, 1973, 1974), many subjects required two operators to describe their data, one for CR trials and the other for $\overline{C R}$ trials. This result constitutes another difficulty for the response-independent theory of Rescorla and Wagner (1972) as well as that of Spence $(1956,1960)$. In general, the effect is one in which the CR operator has a greater limit than does the $\overline{\mathrm{CR}}$ operator. The kind of protocol for which this particular inequality is descriptive is one in which there are fewer transitions between $C R$ and $\overline{C R}$ trials than would be expected on the basis of chance given a single operator limit.

There are two potential sources for the twooperator effect, trial-by-trial incremental-decremental effects linked to $C R$ presence/absence or state changes which last for a span of trials. Although there is no direct evidence, it seems doubtful that the effect is actually a trial-by-trial incrementaldecremental effect. This is because a trial-by-trial effect implies an impact on Trial $\mathbf{N}$ which is correlated with whether or not the CR occurred on Trial $\mathrm{N}-1$. This information would have to be able to survive as many as several minutes between trials, not seriously be disrupted by a US-induced UR on every trial, and not seriously be disrupted by an unpredictable US generated in an intermittent reinforcement schedule. Given that the effect occurs in molecular response systems with relatively limited cost and feedback to the subject, the requirement that a CR-correlated aftereffect survives time and intervening events would seem to be a strong one.

The other alternative which can result in two operators is a series of state changes within a conditioning session. There are two classes of state change to consider, states related to the reception of stimuli and states related to response output. Expressed differently, the former would involve shifts in states reflecting different signal detection likelihoods or differences in delay of signal detection, while the latter would constitute within-session changes in the likelihood of the subject's initiating a sequence of events which culminates in a response, these changes being beyond those reflected in increments in likelihood associated with simple acquisition.

It is not likely that the two-operator effect results either from the reduced likelihood of signal detection or from a delay in signal detection. First, in the present studies, the signal-to-noise ratio of the CS relative to background is quite high, making it unlikely that the signal is not detected. Second, if there is a delay in detecting the signal, then one would expect increases in the latency distribution which would lead responses to overlap the point at which the US occurs, this, in turn, reducing the overall frequency of responses observed during the interstimulus interval. Published latency distributions (e.g., Schneiderman \& Gormezano, 1964) show, however, that the distributions of latencies of nictitating membrane responses are complete in the sense that they are not curtailed at asymptotic performance by US occurrence. The remaining alternatives are state changes affecting $C R$ output. The subject, for a span of trials, may move into a state in which the likelihood of initiating a chain of events which culminates in a response is reduced. There are a number of ways in which this could happen: e.g., failure to go through a rehearsal stage following a trial (see, e.g., Wagner, Rudy, \& Whitlow, 1973), which may be necessary if the signal is to retain its functional value on the subsequent trial; response competition for short periods of time; and emergence, for a span of time, of other responsepotentiating influences such as food deprivation. Another possibility is that the subject moves in and out of states in which some form of inhibitory feedback from prior CS-US presentations operates to reduce the likelihood that a CS occurrence retrieves, from long-term memory, the US representation which is necessary for response occurrence (see, e.g., Pfautz \& Wagner, 1976; Wagner, 1976).

Whatever their origin, the state changes are real in the sense that the number of transitions from response to nonresponse trials is less than would be expected by chance. An avenue of research which remains open, then, is the exploration of classes of events which might well disrupt state shifts, e.g., the introduction of varied and novel stimuli just preceding or following trials. If a class of disrupting events can be isolated, then the number of two-operator subjects would be reduced. Regardless of the specific mechanisms, should it be shown that the subject does change states in a manner like those described above, then the existence of two-operator subjects (in which the two operators are associated with CR presence/absence) does not pose the formidable problem for response-independent theories that would be the case if, in fact, there were trial-bytrial CR-related aftereffects.

\section{Individual Differences}

Individual differences were exhibited in this research at two levels. The first level is customarily acknowledged in research: individual differences in overall mean level of responding and individual differences in parameter estimates for a common model. The second level exhibited is far more troublesome and typically not examined: individual differences in the variables which influence performance within a treatment. Within each treatment combination in the present research, the subjects 
were classified as falling into one of four possible assumption categories. That two or more categories were needed in each treatment serves to emphasize a difficulty in making inferences about a process based upon group averages, and this difficulty is worth exploring.

The basic problem for this study was to determine the way in which US omission affects performance. A typical contrast is to compare the effects of $100 \%$ vs. $50 \%$ reinforcement schedules, and, as Table 1 illustrates, the conclusion based on mean learning curves is clear: performance is lower with the $50 \%$ schedule, as one would predict if there were a decremental effect of US omission. However, use of the two-phase model did show that the bulk of this difference is attributable to an extended duration of Phase 1 , and that there were limited, though real, effects in Phase 2. However, we cannot conclude that the use of the intermittent reinforcement schedule had a small impact on all subjects. To the contrary, it had a noticeable impact on a few subjects. This outcome means that, while it is possible for unpredictable US omission to produce a performance decrement (i.e., require an operator for US omission), it is by no means a common effect. To average the data across subjects can be misleading since the average is across data protocols, the microstructures of which reflect different operating processes. Until we understand the conditions under which US omission can result in a decremental effect, an outcome which is theoretically satisfactory for only a minority of the subjects is not particularly meaningful, or is at most meaningful in denying the generality of a theoretically assumed process. To average data within a treatment in spite of qualitative differences in behavior across subjects is to risk making conclusions about processes which have little substance in the individual subject data. Troublesome though this difficulty may be, it is real and points rather strongly to the need to examine, whenever possible, individual subject protocols. The manipulation of independent variables which can systematically increase or decrease the number of subjects that exhibit a particular pattern of data should provide some insights about what information influences, or what processes govern, behavior. The failure to take into account these qualitative individual differences in behavior would appear to place severe restraint on further theory development.

\section{REFERENCE NOTE}

1. Spurr, C. W. A model of conditioned inhibition. Paper presented at the meeting of the Rocky Mountain Psychological Association, May 1977.

\section{REFERENCES}

Berger, T. W., \& Thompson, R. F. Neuronal plasticity in the limbic system during classical conditioning of the rabbit nictitating membrane response. I. The hippocampus. Brain Research, 1978, 45, 323-346.

Bush, R. R., \& Mosteller, F. Stochastic models for learning. New York: Wiley, 1955.

Clark, C. C., \& Prokasy, W. F. Manipulation of responsecontingent unconditioned-stimulus intensity in human eyelid conditioning: A two-phase model analysis. Memory \& Cognition, $1976,4,277.282$

Coleman, S. R., \& Gormezano, I. Classical conditioning of the rabbit's (Oryctolagus cuniculus) nictitating membrane response under symmetrical CS-US interval shifts. Journal of Comparative and Physiological Psychology, 1971, 77, 447-455.

Estes, W. K. Toward a statistical theory of learning. Psychological Review, 1950, 57, 94-107.

Gormezano, I. Classical conditioning. In J. B. Sidowski (Ed.), Experimental methods and instrumentation in psychology. New York: McGraw-Hill, 1966.

Gormezano, I., \& Coleman, S. R. The law of effect and CR contingent modification of the UCS. Conditional Reflex, 1973, 8, 41-56.

Gormezano, I., \& Moore, J. W. Classical conditioning. In M. H. Marx (Ed.), Learning: Processes. London: Macmillan, 1969.

Gormezano, I., Schneiderman, N., Deaux, E. B., \& Fuentes, I. Nictitating membrane: Classical conditioning and extinction in the albino rabbit. Science, $1962,138,33-34$.

Hesb, D. O. The distinction between "classical" and "instrumental." Canadian Journal of Psychology, 1956, 10, 165-166.

Mitchell, D. G., \& Gormezano, I. Effects of water deprivation on classical appetitive conditioning of the rabbit's jaw movement response. Learning and Motivation, 1970, 1, 199-206.

Perxins, C. C., $J_{R}$. An analysis of the concept of reinforcement. Psychological Review, 1968, 75, 155-172.

Pfautz, P. L., \& Wagner, A. R. Transient variations in responding to Pavlovian conditioned stimuli have implications for the mechanism of "priming." Animal Learning \& Behavior, 1976, 4, 107-112.

Prokasy, W. F. Classical eyelid conditioning: Experimenter operations, task demands, and response shaping. In W. F. Prokasy (Ed.), Classical conditioning. New York: AppletonCentury-Crofts, 1965.

Prokasy, W. F. Developments with the two-phase model applied to human eyelid conditioning. In A. H. Black \& W. F. Prokasy (Eds.), Classical conditioning II. New York: Appleton-Century-Crofts, 1972.

Prokasy, W. F. A two-phase model account of aversive classical conditioning performance in humans and rabbits. Learning and Motivation, 1973, 4, 247-258.

Prokasy, W. F. Discriminated avoidance vs. classical conditioning: A two-phase model analysis. Animal Learning \& Behavior, 1974, 2, 257-261.

Prokasy, W. F., Carlton, R. A., \& Higgins, J. D. Effects of nonrandom intermittent reinforcement schedules in human eyelid conditioning. Journal of Experimental Psychology, 1967, 74, 282-288.

Prokasy, W. F., Clark, C. C., Williams, W. C., \& Spurr, C. W. A classically conditionable skeletal response can be acquired with discriminated punishment contingency. Bulletin of the Psychonomic Society, 1974, 4, 551-553.

Prokasy, W. F., \& Harsanyi, M. A. Two-phase model for human classical conditioning. Journal of Experimental Psychology, 1968, 78, 359-368.

Rescorla, R. A., \& Heth, C. D. Reinstatement of fear to an extinguished conditioned stimulus. Journal of Experimental Psychology: Animal Behavior Processes. 1975, 1, 88-96. 
Rescorla, R. A., \& Wagner, A. R. A theory of Pavlovian conditioning: Variations in the effectiveness of reinforcement and nonreinforcement. In A. H. Black \& W. F. Prokasy (Eds.), Classical conditioning II. New York: Appleton-Century-Crofts, 1972.

Schneiderman, N. Response system divergencies in aversive classical conditioning. In A. H. Black \& W. F. Prokasy (Eds.), Classical conditioning II. New York: Appleton-CenturyCrofts, 1972.

Schneiderman, N., \& Gormezano, 1 . Conditioning of the nictitating membrane of the rabbit as a function of CS-US interval. Joumal of Comparative and Physiological Psychology, 1964, 57, 188-195.

Smith, M. C., Dilollo, V., \& Gormezano, I. Conditioned jaw movement in the rabbit. Journal of Comparative and Physiological Psychology, 1966, 62, 479-483.

SPEnCE, K. W. Behavior theory and conditioning. New Haven: Yale University Press, 1956.

SPENCE, K. W. The roles of reinforcement and nonreinforcement in a single learning. In K. W. Spence (Ed.), Behavior theory and learning. Englewood Cliffs, N.J: Prentice-Hall, 1960.

Thomas, E., \& Wagner, A. R. Partial reinforcement of the classically conditioned eyelid response in the rabbit. Journal of Comparative and Physiological Psychology, 1964, 58, 157-158.

Thompson, R. F. The search for the engram. American Psychologist, 1976, 31, 209-227.

W AGNER, A. R. Priming in STM: An information processing mechanism for self-generated depression in performance. In
T. J. Tighe \& R. N. Leaton (Eds.), Habituation: Perspectives from child development, animal behavior, and neurophysiology. Hillsdale N.J: Erlbaum, 1976.

Wagner, A. R., \& RescorlA, R. A. Inhibition in Pavlovian conditioning: Application of a theory. In R. A. Boakes \& M. S. Halliday (Eds.), Inhibition and learning. London: Academic Press, 1972.

W AGNER, A. R., Rudy, J. W., \& WhitLow, J. W. Rehearsal in animal conditioning. Journal of Experimental Psychology, $1973,97,407-426$.

\section{NOTES}

1. The .05 rejection region was adopted for all statistical contrasts.

2. Our method of categorization required, for assumption D, that at least three asymptotes be distinct. For either three or four asymptotes to be distinct, both the CR present-absent and the US present-absent dimensinns had to influence performance.

3. The failure to find a decremental effect is not an artifact of high response levels. It is clear that increments and decrements within the probability domain did take place or else there would have been no need for the distinction between CR and non-CR operators. Moreover, the data for the appetitive preparation are clearly low enough to reflect omission effects.

(Received for publication July 19, 1977; revision accepted June 27, 1978.) 